
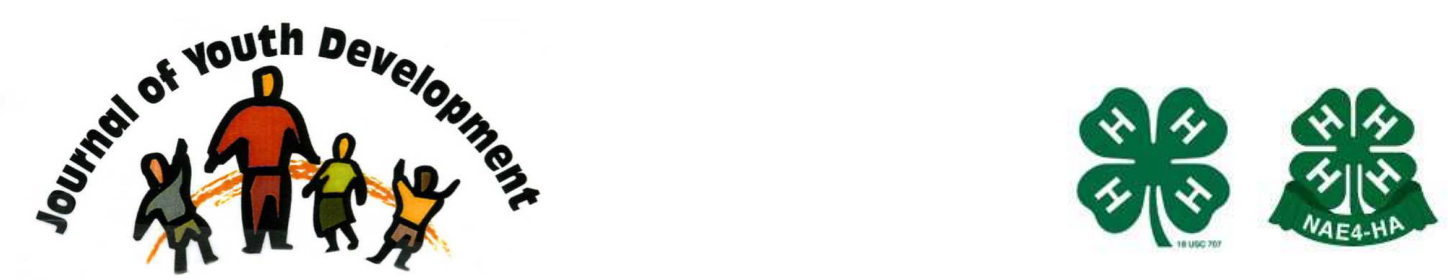

Bridging Research \& Practice

\title{
The Role of Youth Program Leaders in the Use of Technology: Challenges and Opportunities for Youth-Serving Organizations
}

\author{
Mimi Nichter \\ School of Anthropology \\ University of Arizona \\ Tucson, Arizona \\ mimi.nichter@gmail.com \\ Lynne Borden \\ Family Social Science \\ University of Minnesota \\ Minneapolis, Minnesota \\ Imborden@umn.edu \\ Veronica Przybyl \\ School of Anthropology \\ University of Arizona \\ Tucson, Arizona \\ przybyl@email.arizona.edu
}




\title{
JOURNAL OF YOUTH DEVELOPMENT \\ bridging research and practice

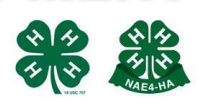

Volume 8, Number 3, Winter 2013

Article 130803PA001

\section{The Role of Youth Program Leaders in the Use of Technology: Challenges and Opportunities for Youth-Serving Organizations}

\author{
Mimi Nichter and Veronica Przybyl \\ University of Arizona \\ Lynne Borden \\ University of Minnesota
}

\begin{abstract}
Youth-serving organizations offer young people an opportunity to gain skills and advance their knowledge of current and evolving technology through experiential learning. The key to ensuring that young people have meaningful learning experiences is directly related to the youth program leader who is responsible for designing and implementing these programs. Programs conducted by well-trained and well-prepared adults are an essential component of community-based interventions. To date, there is relatively limited research on how technology such as smart phones can be used in community-based programs and the success or failure of this as a strategy for delivering information and engaging young people in a program. In this paper, we discuss how technology was introduced into eight programs conducted by youth-serving organizations in the Southwest. We discuss the training of youth program leaders and their experience using technology at their sites, highlighting what worked and what was problematic, how challenges were overcome, and lessons learned.
\end{abstract}

\section{Introduction}

Youth-serving organizations can provide young people with the skills and opportunities needed for making a successful transition to young adulthood by addressing their social, emotional, physical, and educational needs. Indeed, for the past 100 years, youth-serving organizations (e.g., 4-H Youth Development, Boys and Girls Clubs, Girls and Boys Scouting, \& others) have worked to meet the needs of the young people they serve (Borden, Schlomer, \& Wiggs, 2011). There is growing evidence that these programs can and do address health issues (e.g., drugs, 
alcohol, sexual health, and others) directly relevant to youth. Through their participation, young people gain important skills and knowledge that promote their overall positive development (Borden, \& Perkins, 2003; Borden, \& Perkins, 2006; Durlak, \& Weissberg, 2007; Eccles, \& Gootman, 2002).

Training of youth program leaders (sometimes referred to as youth workers) is critical to the creation and maintenance of high quality youth-serving organizations (Mahoney, \& Stattin, 2000; Pierce, Hamm, \& Vandell, 1999). Studies have shown that youth benefit most from programs where the adult leaders have been well trained and benefit less from programs that are less focused and where youth program leaders have insufficient training and experience (Catalano, Berglund, Ryan, Lonczak, \& Hawkins, 1998; Durlak, \& Weissberg, 2007; Vandell, \& Pierce, 2001). Shernoff and Vandell (2007) examined youth engagement in a variety of afterschool enrichment programs (e.g., sports and arts) and found that youth reported the highest levels of engagement in activities that involved both peers and adults, compared to activities involving peers alone. Confirming other studies (Mahoney, \& Stattin, 2000; Pierce, Hamm, \& Vandell, 1999), their findings indicate that youth-serving programs that are conducted by adult leaders who possess knowledge, skills, and expertise can yield the greatest benefit to youth participants.

The importance of skilled program leaders in youth-serving organizations cannot be underestimated. The relationships that adults form with young people within a program often contribute to a youth's decision to continue to participate or not participate in the program (Borden, \& Serido, 2009). Once youth feel connected to a program, the program leader is then responsible for guiding youths' attention to important issues, challenging them, and providing support in meeting these challenges while allowing the youth to explore their abilities and to develop new ones (Pearce, \& Larson, 2006). This open atmosphere helps youth to learn that they can initiate decisions and take part in decision-making with adults, fostering the youths' need for mutual respect (Borden, \& Serido, 2009), empowering youth, and encouraging them to become engaged in many aspects of their lives. Creating such an environment requires a compassionate and savvy adult who is willing and able to make time for youth and their needs.

High quality youth-serving organizations conducted by well-trained and well-prepared adults are an essential component of community-based interventions. These programs often offer programming that is innovative, designed to provide skills and knowledge that young people may not have access to in other places. One approach these programs have used as a tool to engage young people is technology (e.g., robotics, electric cars, handheld gaming devices, and other types of technology). For example, Mahoney (2013) notes that young people are often more responsive to educational programs conducted by youth-serving organizations than those that are offered in a standard classroom.

Today's young people have grown up in a world filled with technology (e.g., computers, cell phones, handheld gaming devices, and other electronic devices). They are accustomed and comfortable with texting, using the internet, playing games online and other technological skills. Therefore, it is important to recognize that the use of technology as a tool in youth-serving programs is a timely and relevant way to engage young people.

To date, there is relatively limited research on how technology can be used in community-based programs and the success or failure of this as a strategy for delivering information and engaging young people in the program. Importantly, findings from one study suggested that integrating computer technology in youth-serving organizations allows youth to gain valuable 
skills that can be beneficial in school and in their future careers (Coe-Regan, \& O'Donnell, 2006). Moreover, providing young people with an opportunity to learn a skill that might personally benefit them may serve as encouragement to actively participate in the program (Coe-Regan, \& O'Donnell, 2006). Thus, it seems important to consider how to utilize technology when designing and implementing programs, recognizing that it is the adults who implement this technology that makes the difference in whether the program is successful. In this paper, we discuss the use of technology in programs conducted by youth-serving organizations and the training of youth program leaders, highlighting what worked and what was problematic, how challenges were overcome, and lessons learned when implementing technology into the program.

\section{Project Background}

This interdisciplinary research project (involving nutritionists, anthropologists, geospatial and computer scientists, and youth development specialists) had as its overall goal to promote physical activity and healthy eating among youth utilizing technology and informal learning approaches (Hingle, et al., 2013). The project was based on earlier formative research with youth conducted by the researchers in which GPS technology was utilized to promote mapping of green spaces and invasive plant species, with a goal of fostering civic engagement and environmental education (Wisneski, 2012). Building on the success of this earlier work and advances in technology which made GPS accessible on smartphones, our research team designed a larger program which provided smartphones loaded with relevant applications (GPS and others) to youth. These apps were specifically developed to assist in identifying and solving a community/environmental problem and the mapping of social spaces of importance to youth. We reasoned that engaging in mapping activities that required exploration of one's physical environment would increase youths' physical activity by encouraging them to walk outdoors.

In this paper, our focus is on the training of youth program leaders to implement smartphonebased programs in their community organization. Specifically, we address the following questions:

1. How much and what type of training do youth program leaders require?

2. After training, do program leaders have sufficient knowledge and skills to implement a technology-based program at their site?

3. What is the experience of program leaders in promoting youth involvement in such programs?

4. What are the challenges and opportunities faced in the training and implementation of technology-based programs in youth-serving organizations?

\section{Methodology}

Eight youth programs in the urban Southwest participated in this project. The focus of these groups varied and included: youth leadership and civic engagement, environmental education, and team sports. Youth programs differed in their organizational structure ranging from a national youth organization like the YMCA to small local youth-serving organizations; programs also differed in the duration of meeting times with youth. Program leaders had varying levels of experience working with youth, with a range from 5 to 15 years of experience.

In this paper, we discuss the involvement of youth-serving organizations in Phase 1 and 2 of the project (2010-2011). Phase 1 and Phase 2 were iterative in that the technology introduced in the first phase was modified and reintroduced in the second phase based on feedback from program leaders and youth participants. During Phase 1, Windows Mobile GPS-enabled HTC Touch Pro smartphones were given to the program leader at each site and to each of the youth 
participants to use for the duration of the program, which ranged from 2-4 months. Training was provided to youth program leaders and participants and involved learning how to use the phone and project applications (GPS, taking pictures, etc.), data upload, and data manipulation, among other topics. Within one to two weeks of receiving the smartphones, each site engaged in a project visioning session in which the program leader worked with the youth to identify how they would use the technology in ways that addressed group interest and dovetailed with the mission of the center. At the conclusion of the program, phones were returned to the project.

Smartphones allowed youth to work both individually or jointly in a group-determined civic engagement project (such as mapping green spaces in their community). The basic mapping software employed on these phones was an in-house developed application (app) which allowed geospatial content to be uploaded into maps. Content from the smartphones and the mapping app were manually transferred to computers by the youth for analysis. Most, but not all of the program sites had computers, and those that did not came to our university office to upload their data.

After some difficulty with the Windows Mobile platform in Phase 1, we shifted phones in Phase

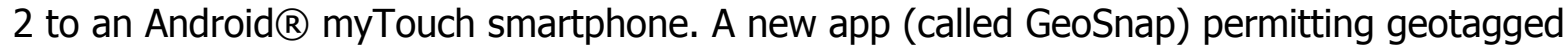
photography and commentary was introduced. One of the end goals of the project was that content created by youth participants on their phones could be sent through 3G or Wifi from the smartphone to our project website which served as a repository for content where youth could share, view, and comment on content created project-wide. The project website contained some aspects of a social network, where participants could contribute content, comment on each other's work, monitor progress, etc. In addition, in Phase II we incorporated "connectors" into the project sites. Connectors were undergraduate students who were trained in the smartphone technology, and who rotated to the project sites serving as "trouble shooters" and assisting the program leaders and the youth in mapping and uploading data.

Members of the anthropology team conducted participant observation during training sessions with program leaders and during program implementation at each site. Overall, 31 observations at eight separate sites took place. Observations generally lasted one to two hours, unless a group field trip was planned, in which case an observation could last anywhere from four to eight hours. Observations were aimed at understanding how program leaders implemented the program, the types of challenges they faced, and how youth used the smartphones. Beyond observation, the anthropologist researchers had informal conversations with participants during observational sessions. Observations were audio recorded and detailed notes were taken. All necessary approvals were obtained from the Institutional Review Board of the University of Arizona.

In addition to observations, 12 interviews were conducted with youth program leaders and 5 with connectors. Some youth program leaders and connectors were interviewed more than once, at various points throughout the project. Several interviews took place after the first phase, with the majority taking place after the second phase. Program leader interviews were either conducted in person or over the phone and, with approval, were audio recorded. Each interview was one to two hours in duration and included general questions about how program leaders felt about the training, the overall project, what was successful, and what was problematic. Similar to the questions asked of the program leaders, connectors were asked about their experiences working with the program and the youth and for their opinions on the challenges and successes faced and suggestions for improvement. 
The connector and program leader interviews were transcribed, carefully read, and hand-coded by the two anthropologist authors. Using these transcripts, key themes were identified that were relevant to program leaders, youth engagement, and enhancing the overall success of the program. Likewise, observation notes were carefully read and hand-coded in order to identify key themes. These form the basis for the discussion in this paper, which focus on the experiences of the program leaders and their role in making this type of intervention successful.

\section{Results}

How much and what type of training do youth program leaders require? Initial training consisted of a half day in-class training led by a skilled facilitator who was knowledgeable in the program goals, smartphone technologies, and the applications that had been developed specifically for our program. The trainer had previous experience working with four of the program leaders on previous technology-based projects. At the time of the first training (Phase 1, 2010), smartphones were not as widely used as they are today. Thus, at the onset, the program leaders' different levels of comfort in using this technology made the training itself challenging, as not all participants had prior experience with smartphones. Therefore, training for some needed to begin at a more basic level than for others. Others had familiarity with smartphone technology but were lacking in familiarity with GPS, and this made addressing the group as a whole difficult.

On the day of the training, program leaders were each given a smartphone that was the same as would be distributed to youth in their program. They participated in an interactive presentation on how to use the phone and apps, viewed online "how to" videos (developed by our project) which could also be used for later reference, and reviewed a manual which had been developed to provide them with background information on the phones and the goals of the program. In addition to how to use the phone and apps, these materials emphasized online and mapping safety when working with youth.

Although the program leaders received smartphones at the workshop so they could train handson and participate in instructive activities, the phones were not ready for distribution and they were unable to keep them after the training. When they received their phones at their program sites (about two weeks later), they felt they had lost some of the knowledge they had gained in the training session. This experience taught us that program leaders needed to have the technology in hand several weeks prior to training, so they could become familiar with its basic functions, and so that following training, they could practice before members of their youth group received their smartphones. In addition, program leaders suggested that they should be given small take home assignments that would allow them to engage with the applications in the same ways the youth would be using them.

Several program leaders noted that they valued the participatory learning that came from brainstorming with leaders from different community-based organizations at their initial training session. They suggested that having monthly meetings of the program leaders who were involved in the smartphone project would help them garner new ideas and would help them work out problems which arose in the field.

Two program leaders were unable to attend the program leader training and therefore took part in on-site training that was less extensive than what was provided to the other program leaders. Each of these program leaders cited lack of training as a barrier to their integrating the 
technology into their programs, thus emphasizing the importance of participation in an in-depth training which involved others who would use the technology in similar ways.

\section{After training, do youth program leaders have sufficient knowledge and skills to implement a technology-based program at their site?}

While one relatively short training session was sufficient to introduce the program leaders to the use of the smartphones and apps, more intensive training was required to facilitate a technology transfer to youth in their programs. During Phase 1, we did not include a translational component into the training, meaning that program leaders were not taught explicitly how to introduce the technology into their particular programs. This translational component varied across projects. For the environmental groups, the program leader(s) needed to explain how the phone and apps were to be used in the field as research tools, while the civic engagement program leaders needed to learn how applications (like mapping) could enhance their mission. One program leader noted the difficulty of playing the role of "facilitator" connecting technology with the goals of her program while ensuring that the technology enhanced the program rather than creating an "additional burden." Thus, we learned that it is important that training of program leaders goes well beyond the technical aspects of the technology to include training in the concrete ways in which the technology can be used with youth.

Prior background in the use of technology—specifically with smartphones—did have an impact on the ability of the program leader to carry out the program. The program leaders who possessed the requisite skills to effectively use and troubleshoot the smartphone technology were able to run their programs smoothly and without an abundance of outside assistance. Those program leaders who were uncomfortable with technology found it difficult to transfer the necessary skills to youth participants in their groups. These program leaders relied heavily on "connectors," the undergraduates who assisted them in the implementation of the program. Program leaders at all sites appreciated the assistance provided by connectors as it lessened their burden and allowed them to focus on their role as group coordinator. This was especially true since the youth participants were not nearly as tech savvy as we initially assumed they would be. This made the translational component of the training and the presence of the connectors particularly important.

\section{What is the experience of program leaders in promoting youth involvement in such programs?}

The structure and dynamics of each youth program was found to be very important in achieving success. Overall, the programs that were highly structured by program leaders were more successful than those that lacked structure or were loosely structured. Programs that were highly structured were characterized by program leaders who had regular and more frequent meeting times with youth participants, and had established programs of longer duration with clear program goals. These groups benefited from greater group cohesion as they were comprised of youth participants who had known one another for long periods of time, thus facilitating their ability to work together. These program leaders also had a clearer idea of what their youth participants found interesting or important and were better able to identify issues that were meaningful to youth that could be addressed using the smartphones and apps. On the other hand, those groups where the program leader had not delineated clear goals had a difficult time understanding the potential uses for the technology. Other groups that lacked cohesion simply had difficulty agreeing upon a project that the youth would find fun and interesting. 
Beyond the structure of the program, we observed that introducing the technology to youth participants was an easier and more natural process for some program leaders than it was for others. Much of this depended on the program leader's ability to use the technology and to recognize the potential it offered to their program. For example, one program leader from an urban local group serving a low-income neighborhood quickly recognized how technology could benefit her group. In her long established group, youth participants often complained about not having enough money to buy and do the things they wanted and she saw the phones and apps as a tool for financial mapping, so youth could track their spending habits. Other groups had more difficulty with this process.

Many program leaders found that the youth participants needed constant reinforcement in order to keep using the technologies to the programs' ends. Program leaders therefore developed certain strategies for maintaining engagement. Some program leaders encouraged competition among their members, keeping track of who collected and uploaded the most data. Another strategy was to encourage group work. Some program leaders felt that youth participants were more likely to engage if their friends were also participating. Similarly, one program leader often sent groups of kids "out on missions." This tactic was much more successful in maintaining youth engagement than expecting youth to actively collect data on their own. This was not always true, however. Some participants found other uses for the technology. One participant, for instance, was passionate about the homeless youth problem and found ways to use her smartphone to gather a list of safe places for homeless youth to go. This program leader encouraged individual, outside uses of the technology, stating, "They can work on their passions, no matter what it is." Program leaders employed various strategies to maintain youth engagement, but those who had a close relationship with their youth and who provided an encouraging atmosphere ultimately experienced more success in the program.

\section{What are the challenges and opportunities in training and implementation of} technology-based programs in youth-serving organizations?

Technology is not a panacea, and its integration into a youth program by program leaders requires an understanding of its potential as well as its limitations. Below we discuss challenges we identified in this process.

Time Commitment: Introducing the use of technology into youth-serving programs required a substantial time commitment on the part of the program leader. Program leader training, youth training, project development, and testing the technology and adjusting it to suit the program needs are all time-consuming endeavors. Many of the program leaders who participated did not anticipate this and thus felt unprepared. This was especially true in programs that had short runs (i.e., summer programs) and had concrete goals that needed to be accomplished. When this time commitment became overwhelming for the program leader or when it conflicted with existing program goals, using technology can become too great a challenge. Furthermore, when too much time is needed to fully and successfully integrate technology or to make the technology work properly, youth may lose interest and become unengaged in the process.

Technological Failures: Each of the program leaders whom we trained did learn to skillfully use the technology, some with the added assistance of tech savvy youth in their group and the connectors. In Phase 1, however, when our apps were newly designed, technology failure created a difficult situation for program leaders. Not only did they have to manage their youth group who were learning new technologies (phones, apps), but they also had to manage group frustrations with phones that did not always work as intended. While some of the reasons for phone failure had to do with the youth themselves (insufficient charge of phones; dropped 
phones, etc.), failure also was caused by apps not working or lack of mobile service as youth programs went on excursions outside the urban areas.

Cost of Supplying Technology: Youth participants were given expensive pieces of technology that had to be carefully managed (preventing youth from making long distance calls, troubleshooting, replacing lost or broken phones, etc.). There was a high cost associated with providing the phones and with keeping the phones in appropriate working order. We had several dedicated people working on the upkeep of the technology. Program leaders felt responsible for the care of the phones, even if it was largely out of their control.

Shift in Group Dynamics: Several program leaders described a shift in their group dynamic after the introduction of the smartphones. They observed that youth participants became less engaged with one another and more engaged with their phones. One program leader observed that youth were communicating via text messages even when face-to-face communication was possible, a phenomenon that was common throughout the duration of the project. Phones could also serve as a distraction from listening to the program leader and other youth group members, allowing one to text friends outside of the group or surf the internet. Thus, smartphone technology has the potential to lessen group cohesion. Along these same lines, it can be difficult for the program leader to promote group work when each individual has the required tools at hand in one convenient piece of technology. One program leader noted that when they used more traditional tools, such as paper maps and recording devices, youth needed to work in groups wherein each member fulfilled a specific role. Using a smartphone, each individual can simultaneously fulfill all roles, meaning that it becomes more difficult to encourage teamwork.

It is worth reiterating that at the time of project inception, much of the utilized technology was relatively new and unfamiliar. In the future, implementing this kind of program should prove easier, as technology is improved, the cost is reduced, and a greater number of people become familiar with its functions. Some of the challenges described above of integrating technology into a youth program, however, may remain.

\section{Opportunities}

Despite the challenges listed above, our team also identified opportunities in working with smartphones in youth-serving organizations.

Fostering relationship: The use of smartphones in youth-serving organizations can serve as a tool that can foster the relationship between the program leader and the youth within their program. First, technology provides a way for program leaders to build on the relationship they have with the young people and to remain in contact with them even when the young people are away from the program. Technology offers program leaders the opportunity to create mentoring leadership roles for tech savvy youth who can assist them in developing projects, training other youth, and troubleshooting the technology. This builds youth-adult collaboration allowing for a horizontal rather than a vertical group dynamic, in which the program leader and the youth can learn from each other.

Developing skills for the $21^{\text {st }}$ century: Using technology as a tool can provide young people the opportunity to learn many important skills (leadership, mapping skills, basic coding skills, and others). Further, the use of technology can assist program leaders in empowering young people to address critical social issues within the community using the skills they have learned. For example, in one of the project sites, youth focused a group project on financial mapping, which 
enabled them to track how they spent their money and to learn about budgeting. Clearly these are skills that are applicable to their present experience as well as their future well-being. At another site, youth identified community service and volunteer opportunities for teens throughout the city, while at another project site, youth collected data on invasive local species growing in the urban area.

Organizational tool for program leaders: Using the smartphones, program leaders could better plan their group activities and could more easily organize themselves via mass text messages. This could give program leaders a jumpstart on future meetings and could encourage group cohesion and involvement in planning activities. Youth could also more easily be involved in planning future activities. For example, youth at one site used their smartphone communication to coordinate a fundraising activity.

Disseminating project results: Program leaders recognized the need for a tangible end product from a technology project, noting that providing a platform for youth to present their projects to other youth would be worthwhile. This was especially true when the youth had collected data that could positively impact other youth or garner interest in or awareness of important issues such as environmental sustainability or youth homelessness. The creation of an end product also allows youth to see what is possible given the right tools. For example, the environmental group program leaders envisioned a youth-produced, online natural history in which youth could take geo-tagged photos of native plant and animal species, providing location and habitat information. Thus, findings from their project could provide the community with usable data which could document changes in their local environment.

\section{Discussion/Conclusion}

There is an ever growing demand for those individuals who can successfully use technology in today's society. The lack of highly skilled individuals who can successfully work in the industries related to science, technology, engineering and mathematics (STEM) has become a national focus at the local, state, and national levels. Educational institutions at all levels are trying to create learning opportunities that will increase not only the level of knowledge of the STEM areas, but also interest in pursuing these areas as careers. Taraman (2010) notes that there are too few students entering into fields related to STEM careers and thus it is critical to find ways in which to support young people who have an interest in these fields of study. Youth-serving organizations offer young people the opportunity to explore and advance their knowledge of current and evolving technology through experiential learning opportunities. These organizations can then serve as a gateway for encouraging and supporting exploration by young people in these STEM areas. The key to ensuring that young people have rich and meaningful learning experiences is directly related to the program leader who is responsible for designing and implementing these programs.

Although there were challenges in implementation of this innovative program, the use of smartphones in community-based organizations can be beneficial for the program leader. Technology provides a way for increased communication between program leaders and youth, and has the potential to enhance these relationships. Some program leaders were able to rely on technologically knowledgeable youth to aide them in developing projects, training other youth in program activities, and troubleshooting. This can be particularly important for older youth because it not only engages them but also allows them to have a mentoring role, potentially grooming them to be youth leaders. 
Using technology as a tool to further the goals of youth-serving programs provides the opportunity to learn many important skills. Program leaders felt that the use of technology enabled youth participants to learn mapping and GPS, photography, and basic internet skills. Further, the use of technology, especially for civic engagement, can help program leaders empower youth with an experiential tool to become informed and active members of their communities.

Finally, there is a growing literature that suggests that youth program leaders are the lynch pin to ensure that there is a positive benefit to youth participants (Smith, Peck, \& Denault, 2010; Walker, et al., 2005). The ability of the program leader to implement a program that will offer knowledge, skills and opportunities for further exploration to youth is key to both program success and positive youth outcomes. Given the importance of technological competence in today's world, it is clear that youth program leaders are well positioned to help youth develop skills to survive and thrive in the digital world.

\section{References}

Borden, L.M., \& Perkins, D.F. (2003). Volunteers as essential members of community collaborations. The Journal of Volunteer Administration, 21(3), 20-24.

Borden, L.M., \& Perkins, D.F. (2006). Community youth development professionals: Providing the necessary supports. Child and Youth Care Forum, 35(2), 101-158.

Borden, L.M., Schlomer, G.L., \& Wiggs, C.W. (2011). The Evolving Role of Program Leaders. Journal of Youth Development, 6(3), 126-138.

Borden, L., \& Serido, J. (2009). From program participant to engaged citizen: A developmental journey. Journal of Community Psychology, 37, 423-438.

Catalano, R.F., Berglund, M.L., Ryan, J.A.M., Lonczak, H.S., \& Hawkins, J.D. (1998). Defining and evaluating positive youth development. In Positive Youth Development in the United States: Research Findings on Evaluations of Positive Youth Development Programs.

Coe-Regan, J.R., \& O'Donnell, J. (2006). Best Practices for Integrating Technology and Service Learning in a Youth Development Program. Journal of Evidence-Based Social Work, 3, 201-220.

Durlak, J.A., \& Weissberg, R.P. (2007). A meta-analysis of after school programs that seek to promote personal and social skills in children and adolescents. Journal of Educational Psychology, 36, 211-221.

Eccles, J.S., \& Gootman, J.A. (Eds.). (2002). Community programs to promote youth development. Washington, DC: National Academy Press.

Hingle, M., Nichter, M., Medeiros, M., Grace, S. (2013). Texting for Health: The Use of Participatory Methods to Develop Healthy Lifestyle Messages for Teens. Journal of Nutrition Education and Behavior, 45(1), 12-19. 
Mahoney, J.L., \& Stattin, H. (2000). Leisure activities and adolescent antisocial behavior: The role and structure of social context. Journal of Adolescence, 23, 113-127.

Mahoney, M. (2013). Reinventing the electric car: Education beyond the classroom. Technology \& Engineering Teacher, 72 (7), 6-12.

Pearce, N., \& Larson, R. (2006). How teens become engaged in youth development programs: The process of motivational change in a civic activism organization. Applied Developmental Science, 10, 121-131.

Pierce, K.M., Hamm, J.V., \& Vandell, D.L. (1999). Experiences in after-school programs and children's adjustment in first-grade classrooms. Child Development, 65, 440-457.

Shernoff, D.J., \& Vandell, D.L. (2007). Engagement in after-school program activities: Quality of experience from the perspective of participants. Journal of Youth and Adolescence, 36, 891903.

Smith, C., Peck, S.T., \& Denault, A. (2010). Quality at the point of service: Profiles of practices in after-school settings. American Journal of Community Psychology, 45, 358-369.

Taraman, K.S. (2010). Preparing the Next American Manufacturing Workforce. Techniques: Connecting Education \& Careers, 85(3), 30-33.

Vandell, D.L., \& Pierce, K.M. (2001). Experiences in after-school programs and child well-being. In J.L. Mahoney (Chair), Protective aspects of after-school activities: Processes and mechanisms. Paper symposium conducted at the biennial meeting of the Society for Research in Child Development, Minneapolis, MN.

Walker, J.A., Marczak, M., Blythe, D.A., \& Borden, L. (2005). Designing youth development programs: Toward a theory of developmental intentionality. In J.L. Mahoney, R.W. Larson, \& J.S. Eccles (Eds.), Organized activities as contexts of development: Extracurricular activities, after-school and community programs (pp. 399-418). Mahwah, NJ: Erlbaum.

Wisneski, K. (2012). Reconnecting youth with community and environment: Keys to civic engagement education program success. (Master's Thesis) School of Natural Resources and the Environment, University of Arizona.

(c) Copyright of Journal of Youth Development $~$ Bridging Research and Practice. Content may not be copied or emailed to multiple sites or posted to a listserv without copyright holder's express written permission. Contact Editor at: patricia.dawson@oregonstate.edu for details. However, users may print, download or email articles for individual use.

ISSN 2325-4009 (Print); ISSN 2325-4017 (Online) 